\title{
PENGARUH SEBARAN DATA GROUND CONTROL POINT (GCP) DALAM PENGOLAHAN DATA FOTO UDARA PADA AREA IN-PIT MAPPING MENGGUNAKAN DRONE QUADCOPTER DJI PHANTOM 4 RTK BERBASIS BASE GPS METODE REAL TIME KINEMATIC (RTK)
}

\author{
Ryan Nugraha $^{1}$, Sigit Putrasakti ${ }^{2}$ \\ ${ }^{I}$ Geodetics PT Arutmin Indonesia, Departemen Engineering, Satui \\ ${ }^{2}$ Geologist PT Arutmin Indonesia, Departemen Mineral Resources, Balikpapan
}

\begin{abstract}
ABSTRAK
Teknik pengambilan foto udara yang saat ini sedang berkembang, tidak bisa dipungkiri lagi bahwa teknologi Unmanned Aerial Vehicle (UAV), khususnya drone merupakan salah satu teknologi yang sangat efektif dan efisien dalam melakukan kegiatan mapping (pemetaan). Kegiatan mapping menggunakan drone ini juga tidak luput dari industri pertambangan, khususnya tambang batu bara yang saat ini mulai popular menggunakan salah satu teknologi yang modern ini. Salah satu jenis UAV yang digunakan PT Arutmin Indonesia adalah drone quadcotper DJI Phantom 4 RTK yang berbasis base GPS metode Real Time Kinematic (RTK). Kegiatan mapping menggunakan drone diperlukan beberapa titik ikat atau kontrol di permukaan tanah yang disebar di area mapping yang dikenal dengan Ground Control Point (GCP). GCP berfungsi sebagai titik ikat atau kontrol di permukaan tanah. Sebaiknya GCP disebar merata di permukaan tanah area mapping yang areanya bebas dari obstacles, dan tidak mengganggu kegiatan penambangan agar hasil dari pengolahan data diharapkan menghasilkan data orthophoto dan kontur topografi yang presisi dan akurat. Kegiatan mapping yang dilakukan PT Arutmin Indonesia ini dilakukan di area in pit dump dengan sebaran enam data GCP yang disebar di ujung-ujung dan tengah batasan area mapping. GCP yang tidak di sebar merata di area mapping akan menghasilkan data orthophoto dan kontur topografi yang tidak presisi dan akurat. Ini disebabkan adanya area mapping yang tidak terikat/terkontrol oleh GCP. Area mapping yang tidak tercover GCP, dominan orthophoto yang dihasilkan tidak sesuai dengan aktual kondisi in pit dump. Orthophoto in pit dump ini, keadaan bench dump akan terlihat tidak lurus atau terpisah atau tidak menyambung karena posisi horizontal yang dihasilkan tidak presisi dan akurat. Begitu juga dengan data topografi, apabila area mapping tidak tercover GCP, akan menimbulkan variance $+/-5-10 \mathrm{~m}$ pada posisi horizontal (easting dan northing) dan 3-5 m pada posisi vertical (elevation). Dengan demikian data GCP yang disebar merata di area mapping merupakan salah satu parameter untuk menghasilkan data orthophoto dan kontur yang presisi dan akurat. GCP yang disebar merata di area mapping akan memberikan pengaruh terhadap ketelitian rektifikasi yang ditunjukkan melalui nilai Root Mean Square Error (RMSE) ketelitian jarak dan posisi (koordinat).
\end{abstract}

Kata Kunci: GCP, mapping, in pit dump, rektifikasi

\begin{abstract}
The technique of taking aerial photographs is currently developing, it is undeniable that the technology of Unmanned Aerial Vehicle (UAV), especially drones, is one of the technologies that is very effective and efficient in conducting mapping activities. Mapping activities using drones are also not spared from the mining industry, especially coal mining which is currently gaining popularity using one of these modern technologies. One type of UAV used by PT Arutmin Indonesia is the DJI Phantom 4 RTK quadcotper drone based on the GPS Real Time Kinematic (RTK) method. Mapping activities using drones require a number of grounding points or controls that are
\end{abstract}


spread out in a mapping area known as a Ground Control Point (GCP). GC Work as a bonding point or control at ground level. GCP should be distributed evenly on unobstructed mapping surface, and there is no mining activity so that the results of data processing are expected to produce precise and accurate orthophoto and topographic contour data. The mapping activity carried out by PT Arutmin Indonesia was carried out in an area in the pit dump with the distribution of six GCP data distributed at the edges and the mapping of the middle area. GCP that is not spread evenly in the mapping area will produce orthophoto data and topographic contours that are not precise and accurate. This represents the existence of an area mapping that is not approved / controlled by GCP. Mapping the area that is not covered by GCP, the dominant orthophoto produced is not in accordance with the actual conditions in the pit dump. Orthophoto in this pit dump, the state of the dump bench will look not straight or separate or not connect because the resulting horizontal position is not precise and accurate. Likewise with topographic data, mapping the rejected area is not covered by GCP, will cause variance +/- 5-10 $\mathrm{m}$ in the horizontal position (east and north) and 3-5 $\mathrm{m}$ vertical position (elevation). Thus GCP data distributed evenly in the mapping area is one of the parameters to produce precise and accurate orthophoto and contour data. GCP that is spread evenly in the mapping area will give effect to the accuracy of rectification studied through the value of Root Mean Square Error (RMSE) accuracy of distance and position (coordinates).

Keywords: GCP, mapping, in pit dump, rectification

\section{A. PENDAHULUAN}

\section{A.1. Latar Belakang}

Teknik pengambilan data foto udara menggunakan teknologi Ummanned Aerial Vehicle (UAV), khususnya drone salah satu teknologi dalam melakukan kegiatan mapping (pemetaan topografi) yang juga merupakan salah satu teknologi penginderaan jauh yang sedang berkembang di industri pertambangan. Penginderaan jauh adalah suatu pengamatan oyek suatu daerah tanpa melalui kontak langsung dengan oyek tersebut (Lillesand, dkk, 2004). Penginderaan jauh mampu menghasilkan citra atau orthophoto dengan resolusi yang tinggi dengan melalui beberapa tahapan pengolahan data antara lain: image enhancement, mosaicking, dan koreksi geometrik. Tujuan dari koreksi geometrik yaitu untuk melakukan retifikasi (pembetulan) atau retorasi (pemulihan) citra atau orthophoto agar koordinat sesuai dengan koordinat geografis (Purwadhi, 2001). Proses rektifikasi membutuhkan koordinat ground control point $(G C P)$ sebagai titik kontrol atau ikat di permukaan tanah (surface) yang berfungsi untuk mengkoreksi dan memperbaiki data citra atau orthophoto secara keseluruhan. Tingkat akurasi titik control atau ikat tanah sangat bergantung pada GPS yang digunakan dan jumlah sampel titik terhadap lokasi dan waktu pengambilan (Hasyim, 2009).

Dalam kegiatan pemetaan topografi, salah satu jenis $U A V$ yang digunakan PT Arutmin Indonesia adalah drone quadcotper DJI Phantom 4 RTK yang berbasis base GPS metode Real Time Kinematic (RTK). Kegiatan mapping yang dilakukan PT Arutmin Indonesia ini dilakukan di area in pit dump dengan sebaran enam data $G C P$ yang disebar di ujung-ujung dan tengah batasan area mapping. Dalam penelitian ini akan dilakukan analisa terhadap penyebaran atau pendistribuasian $G C P$ dan penggunaan base GPS dengan metode RTK. Diharapkan dalam penelitian ini diperoleh pengaruh sebaran atau distribusi data $G C P$ pada ketelitian dan keakuratan data topografi yang dihasilkan dengan menggunakan base GPS metode RTK. 


\section{B. METODOLOGI PENELITIAN}

\section{B.1. Data dan Peralatan \\ - Data}

Data yang digunakan dalam penelitian ini adalah data citra satelit Digital Globe Worldview-

1,2,3, dan GEOEye tahun 2018, pengukuran ground control point, dan base GPS metode RTK.

\section{- Peralatan}

Peralatan yang digunakan dalam penelitian ini adalah drone quadcotper DJI Phantom 4 RTK, GPS Trimble R8S tipe geodetic, software agisoft, dan minescape.

\section{B.2. Wilayah Penelitian dan Akuisisi Data}

Wilayah penelitian dilakukan di area PKP2B PT Arutmin Indonesia area Mulia, site tambang Satui. Area Satui berada dalam Kabupaten Tanah Bumbu, Kalimantan Selatan dengan geografis yang dominan masih ditumbuhi hutan, tanaman sawit, dan karet. Pengambilan dan pengolahan data penelitian ini dapat dilihat dari diagram alir pada Gambar 1.

\section{HASIL DAN PEMBAHASAN}

\section{C.1. Pengambilan dan Pengolahan Data}

Sebelum dilakukan pengambilan data, terlebih dahulan dilakukan penentuan dan pemasangan titiktitik GCP dan base GPS RTK. Dalam penelitian ini dilakukan pemasangan enam titik GCP dan satu GPS tipe geodetic dengan metode RTK. Titik-titik GCP dan base GPS yang dipasang akan digunakan sebagai parameter dalam pengolahan orthophoto dan permukaan topografi (kontur).

Setelah titik-titik GCP dan base GPS dipasang, selanjutnya drone diterbangkan dengan kamera drone tegak lurus terhadap permukan objek yang akan diambil. Dalam penelitian ini permukaan aktivitas in-pit dump. Data-data yang dihasilkan oleh drone berupa foto-foto yang mempunyai nilai koordinat yang akan digunakan pada saat pengolahan data menggunakan software agisoft. Hasil dari pengolahan data foto udara penelitian ini adalah berupa kontur topografi atau lebih dikenal dengan DEM (Digital Elevation Model) atau DTM (Digital Terrain Model) dan orthomozaic. Namun pada penelitian hanya data kontur tografi yang akan di kaji. Setelah diperoleh kontur dengan menggunakan software agisoft, selanjutnya data kontur akan di analisis menggunakan software minescape. Hasil pengolahan data foto udara berupa kontur menggunakan GCP dan base $G P S$, akan dilakukan komparasi dengan hasil pengolahan data foto udara yang tidak menggunakan $G C P$ dan base GPS. Kontur-kontur tersebut akan dibuat model section-nya, diharapkan agar diperoleh analisis yang akurat dan presisi pada saat mengkomparasi kedua kontur tersebut. Komparasi kedua kontur ini juga menggunakan koordinat-koordinat objek yang aktual dan jarak dilapangan, seperti jalan, high wall, crest, toe, dan aktivitas in-pit dump.

Berikut kontur hasil pengolahan data foto udara menggunakan titik-titik GCP dan base GPS yang dipasang di atas permukaan tanah (Gambar 3)

Hasil pengolahan data foto udara menggunakan titik-titik GCP dan base GPS yang dipasang di atas permukaan tanah dapat dilihat kontur high wall dan aktivitas in-pit dump di area penambangan yang masih aktif. Toe dan crest dump tergambar dengan baik. Interval dari kontur diatas adalah 1 meter agar detil progress penambangan terlihat dengan baik dan jelas. Pemasangan titik-titik kontrol/ikat (titik-titik $G C P$ ) dan base GPS yang digunakan sangat berperan penting dalam keakuratan dan presisi data, sehingga pengambilan data foto udara dapat dilakukan secara real time kinematic $(R T K)$. Pada penelitian ini akan mengbandingkan pengambilan data foto udara menggunakan $G C P$, base GPS dan tidak menggunakan GCP. Berikut kontur hasil pengolahan data foto udara yang tidak menggunakan GCP dan base GPS (Gambar 4) 


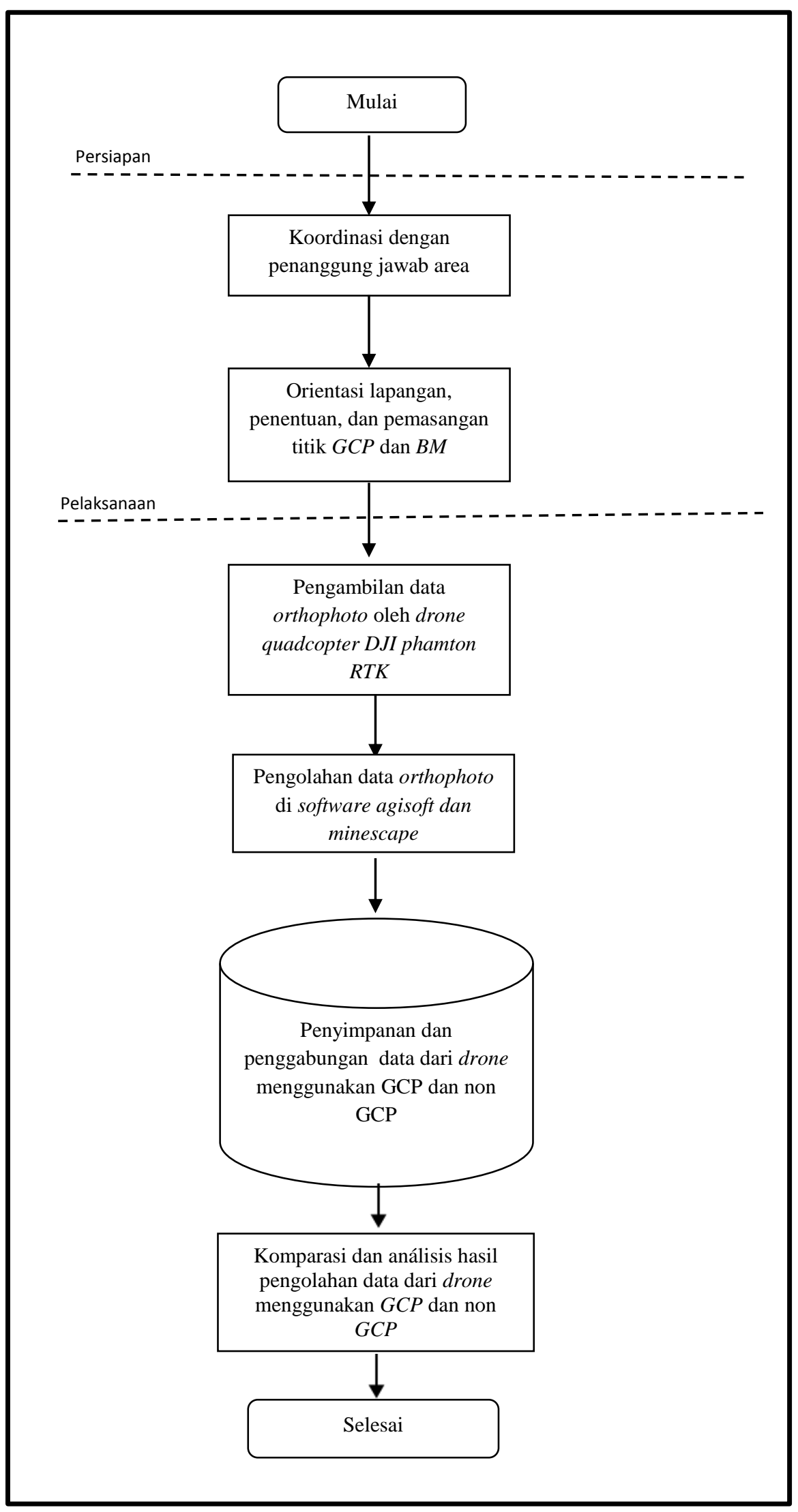

Gambar 1. Diagram alir pengambilan dan pengolahan data 


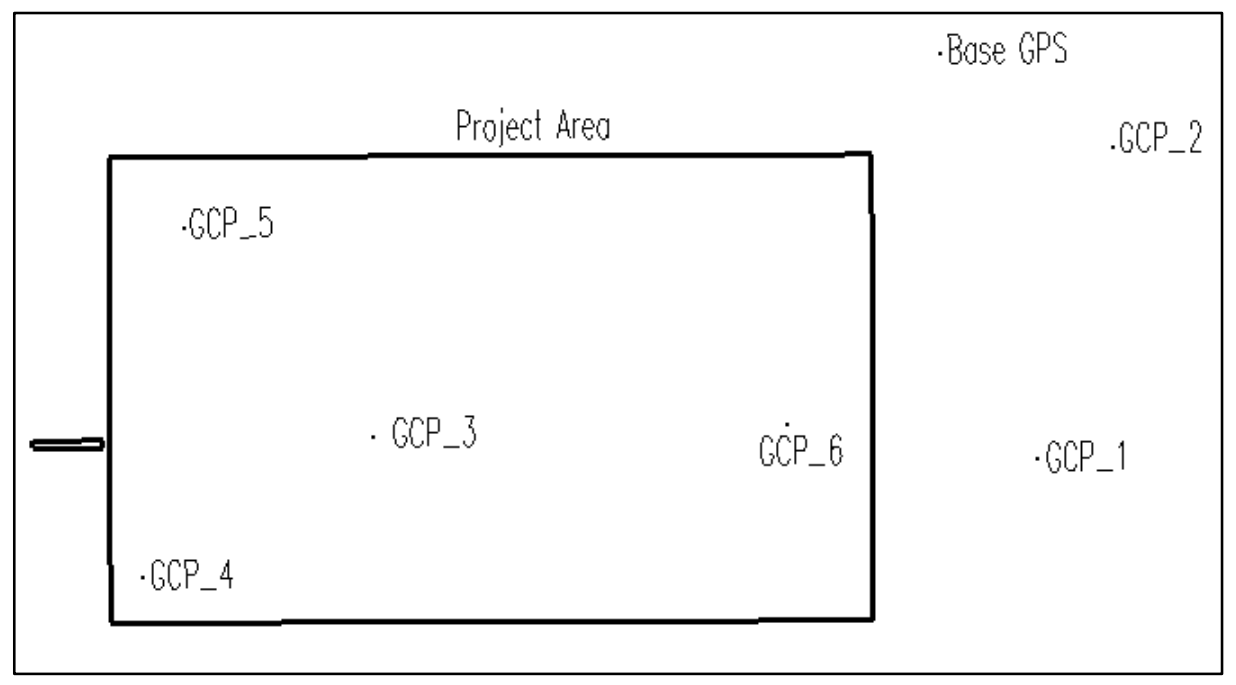

Gambar 2. Sebaran titik-titik GCP dan base GPS

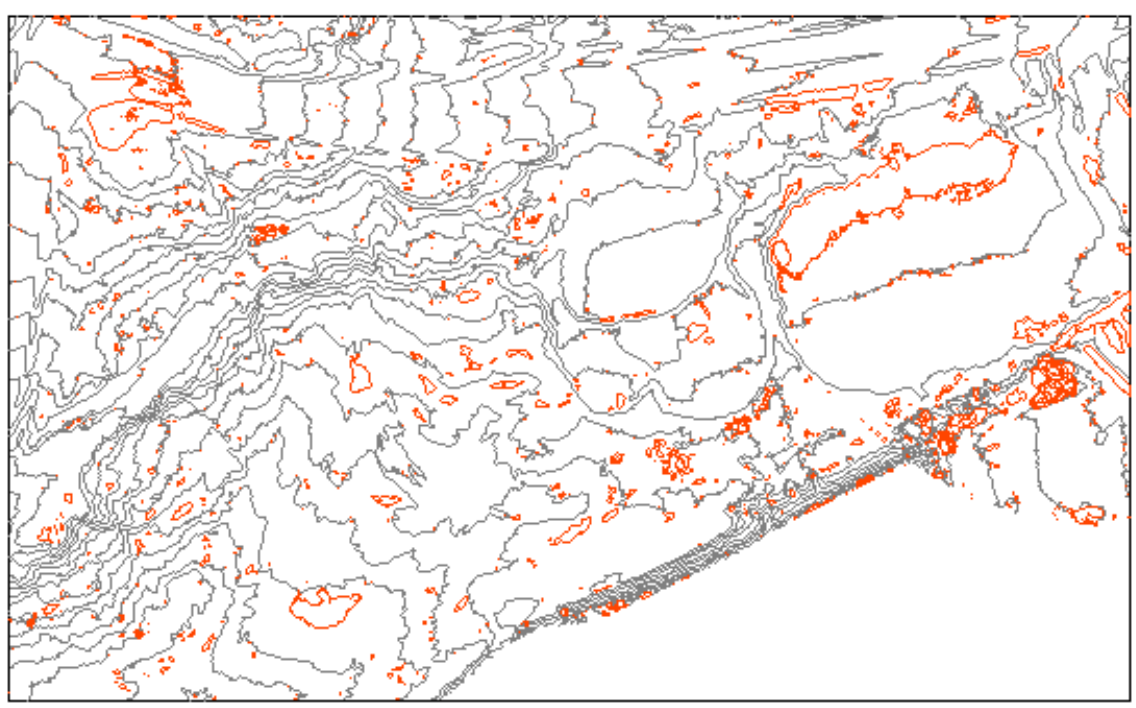

Gambar 3. Hasil pengolahan data foto udara menggunakan titik-titik $G C P$

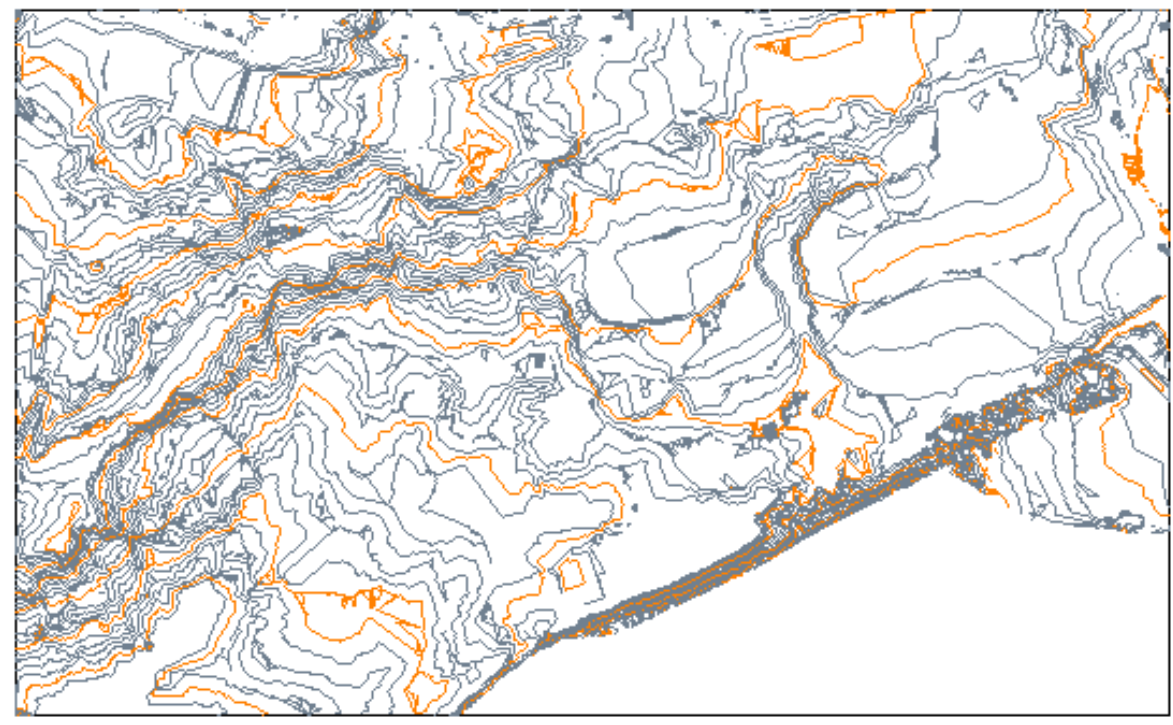

Gambar 4. Hasil pengolahan data foto udara tidak menggunakan titik-titik $G C P$ 
Hasil pengolahan data foto udara yang tidak menggunakan titik-titik GCP dan base GPS dapat dilihat kontur high wall dan aktivitas in-pit dump di area penambangan yang masih aktif. Toe dan crest dump kurang tergambar dengan baik. Walaupun interval kontur yang digunakan sama dengan interval kontur yang sebelumnya yaitu 1 meter. Kontur yang dihasilkan kurang presisi dan akurat yang disebabkan tidak adanya titik-titik kontrol (ttitik-titk $G C P$ ) yang dipasang di atas permukaan tanah dan base GPS yang tidak digunakan. Sehingga pengambilan data foto udara tidak dapat dilakukan secara real time kinematic (RTK).

\section{PEMBAHASAN}

Setelah diperoleh kontur menggunakan titik-titik GCP, base GPS dan kontur yang tidak menggunakan titik-titik GCP, base GPS, selanjutnya dilakukan komparasi terhadap kedua kontur tersebut. Komparasi kedua kontur ini akan dibuat model section-nya dengan menggunakan koordinat-koordinat objek yang aktual dan jarak dilapangan, seperti jalan, high wall, crest, toe, dan aktivitas in-pit dump. Sebelum membuat model section, dilakukan pembuatan garis section terlebih dahulu, yang bertujuan agar dapat membatasi area yang akan dilakukan analisis.

Garis-garis section yang dibuat sebanyak 7 garis section yang dimulai dari arah barat ke timur (AA'), utara ke selatan (B-B', C-C', D-D', E-E', F-F', dan G-G') dan sebaiknya dekat dengan titiktitik GCP. Hasil dari section model kedua kontur tersebut bisa dilihat dari Gambar 5.

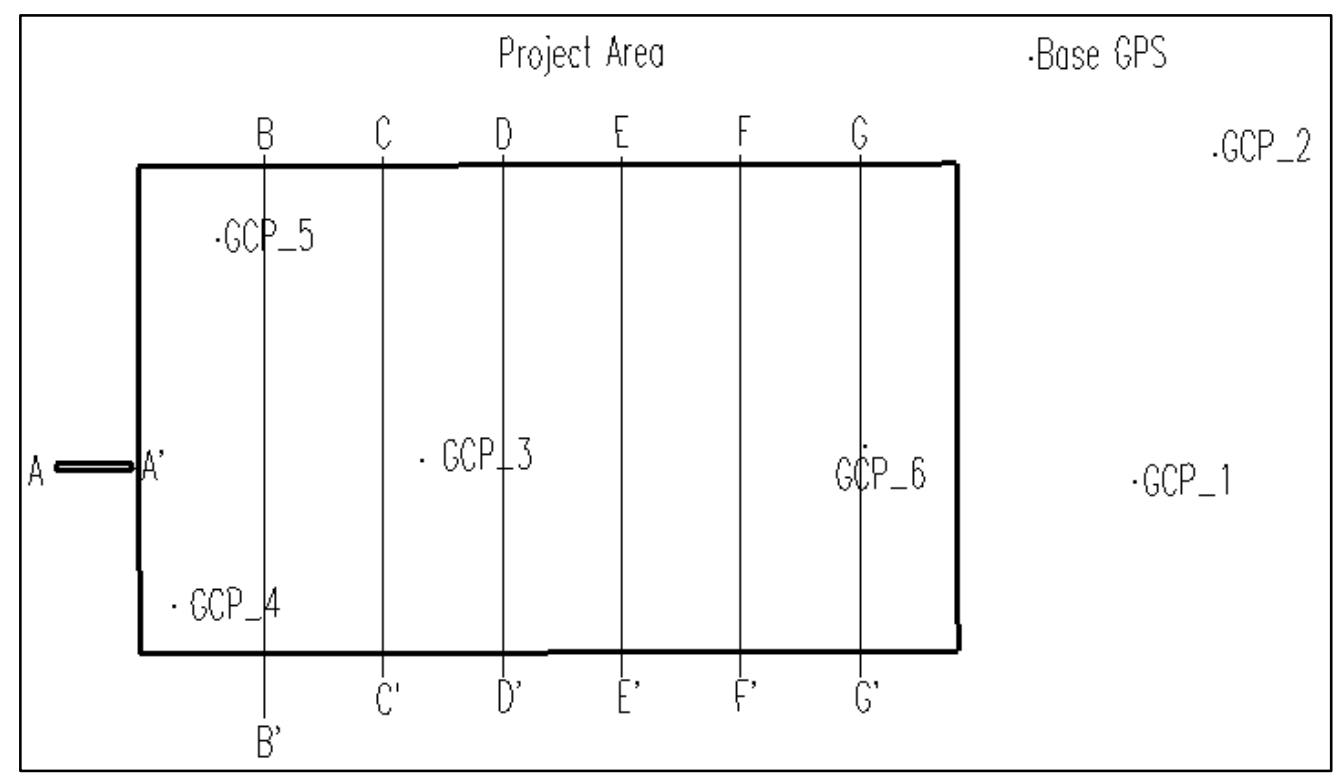

Gambar 5. Garis section

- Garis warna hijau adalah data topografi yang dihasilkan drone menggunakan GCP dan base GPS, dan garis warna magenta adalah data topografi yang dihasilkan drone tidak mengunakan GCP dan base GPS.

- Section A-A', komparasi kontur di area surface dump yang relatif datar. Variance kedua kontur relatif tidak terlalu besar dengan variance easting: $1.254 \mathrm{~m}$, northing: $1.428 \mathrm{~m}$, dan elevation: $0.908 \mathrm{~m}$. Diperoleh variance posisi horizontal sebesar $1.900 \mathrm{~m}$.

- Section B-B', komparasi kontur di area toe dump. Variance kedua kontur sedikit lebih besar dengan variance easting:4.620 m, northing: $0.881 \mathrm{~m}$, dan elevation: $2.420 \mathrm{~m}$. Diperoleh variance posisi horizontal sebesar $4.703 \mathrm{~m}$. 
- Section C-C', komparasi kontur di area crest dump. Variance kedua kontur relatif hampir sama dengan section B-B' dengan variance easting: $4.646 \mathrm{~m}$, northing: $0.251 \mathrm{~m}$, dan elevation: $3.321 \mathrm{~m}$. Diperoleh variance posisi horizontal sebesar $4.653 \mathrm{~m}$.

- Section D-D', komparasi kontur di area jalan. Variance kedua kontur relatif tidak terlalu besar dengan variance easting: $2.659 \mathrm{~m}$, northing: $0.624 \mathrm{~m}$, dan elevation: $0.358 \mathrm{~m}$. Diperoleh variance posisi horizontal sebesar: $2.731 \mathrm{~m}$.

- Section E-E', komparasi kontur di area surface dump. Variance kedua kontur relatif lebih besar dari section A-A' dengan variance easting: $4.438 \mathrm{~m}$, northing: $3.573 \mathrm{~m}$, dan elevation: $4.011 \mathrm{~m}$. Diperoleh variance posisi horizontal sebesar $5.698 \mathrm{~m}$ dan posisi vertikal lebih besar dari section A-A' dengan variance sebesar 3.103 m yang mana di area surface dump juga.

- Section F-F', komparasi kontur di area surface dump. Variance kedua kontur relatif lebih besar dari section A-A' dan lebih kecil dari section E-E' dengan variance easting: $1.527 \mathrm{~m}$, northing: $3.101 \mathrm{~m}$, dan elevation: $4.849 \mathrm{~m}$. Diperoleh variance posisi horizontal sebesar $3.457 \mathrm{~m}$ dan posisi vertikal lebih besar dari section A-A' dengan variance sebesar $3.941 \mathrm{~m}$ dan section E-E' sebesar $0.838 \mathrm{~m}$.

- Section G-G', komparasi kontur di area high wall. Variance kedua kontur relatif lebih besar dari enam section area di atas dengan variance easting: $10.789 \mathrm{~m}$, northing: 10.820 $\mathrm{m}$, dan elevation: $15.280 \mathrm{~m}$. Diperoleh variance posisi horizontal sebesar $15.280 \mathrm{~m}$.

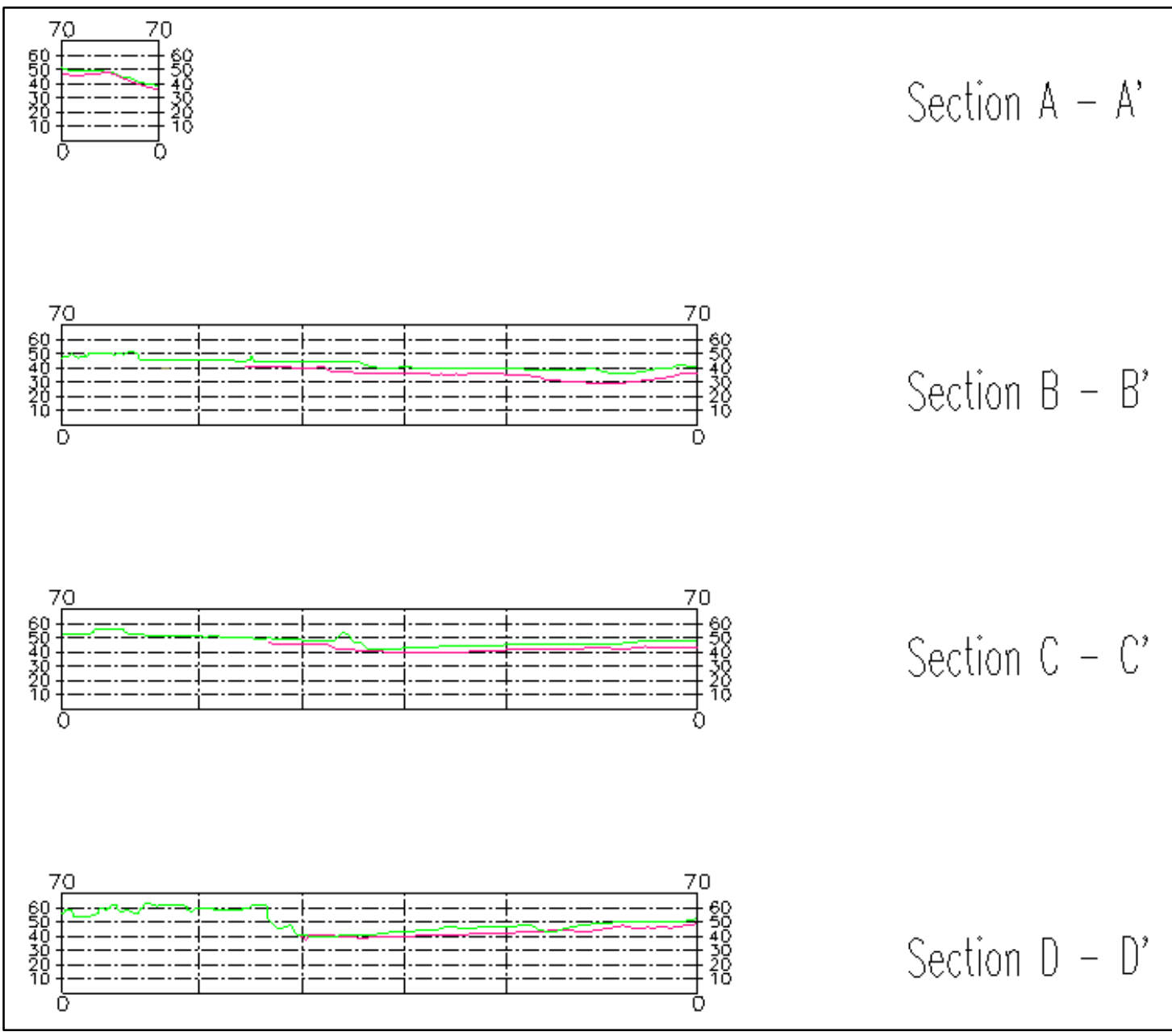

Gambar 6. Section A-A', B-B', C-C', dan D-D' 


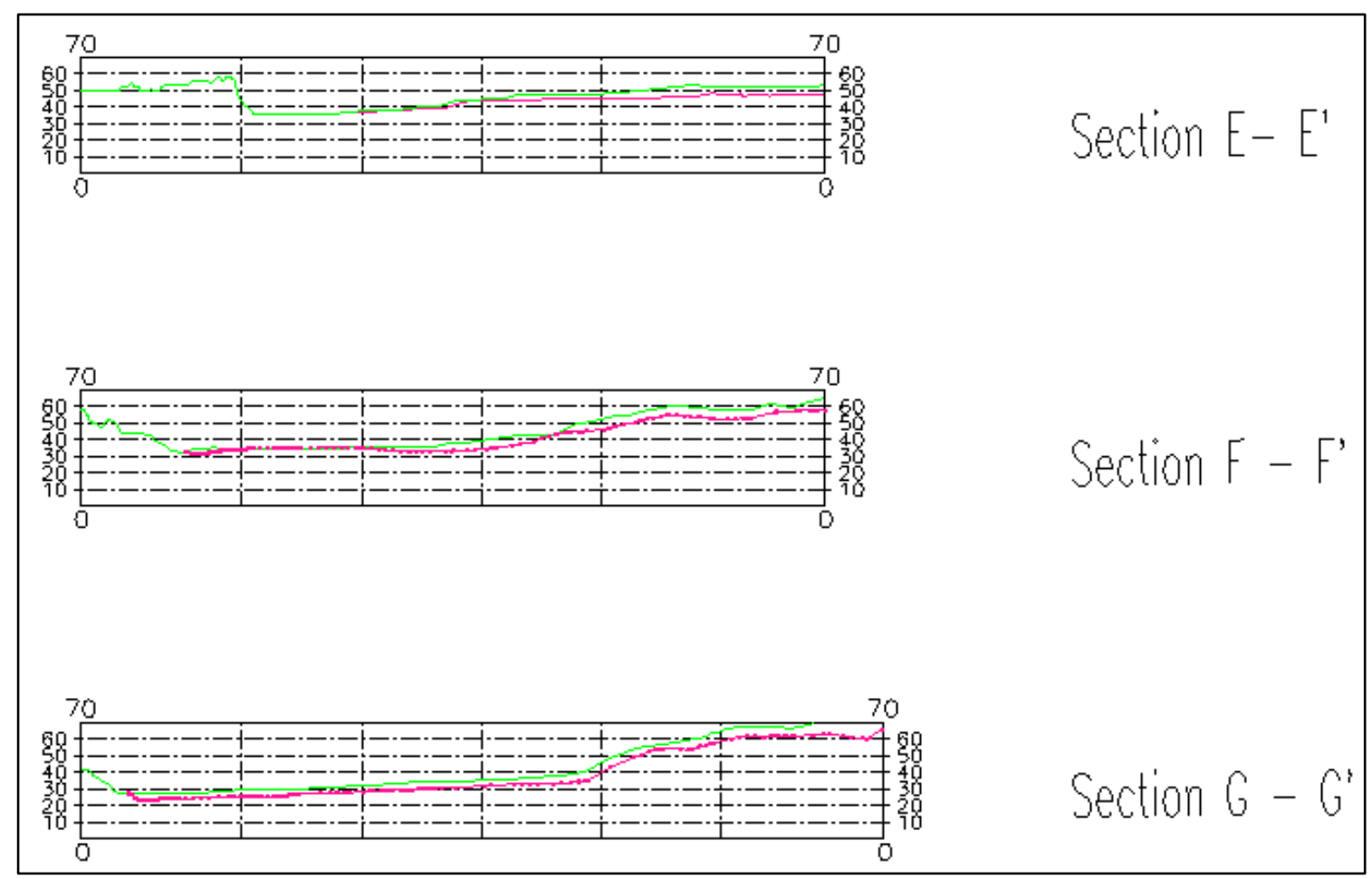

Gambar 7. Section E-E', F-F', dan G-G

\section{E. KESIMPULAN}

\section{E.1. Kesimpulan}

Komparasi dari 7 section di atas dapat disimpulkan ke tabel berikut:

Tabel 1. Komparasi kontur dengan tujuh section

\begin{tabular}{cccccc}
\hline \multirow{2}{*}{ Section } & \multicolumn{3}{c}{ Variance } & Area \\
\cline { 2 - 6 } & Easting $(\mathbf{m})$ & Northing $(\mathbf{m})$ & Elevation $(\mathbf{m})$ & Posisi Horizontal $(\mathbf{m})$ & \\
\hline A-A' & 1.254 & -1.428 & 0.908 & 1.900 & Surface dump \\
\hline B-B' $^{\prime}$ & -4.620 & 0.881 & 2.420 & 4.703 & Toe dump \\
\hline C-C' $^{\prime}$ & 4.646 & -0.251 & 3.321 & 4.653 & Crest dump \\
\hline D-D' & -2.659 & -0.624 & 0.358 & 2.731 & Road \\
\hline E-E' & -4.438 & 3.573 & 4.011 & 5.698 & Surface dump \\
\hline F-F' & 1.527 & -3.101 & 4.849 & 3.457 & Surface dump \\
\hline G-G' & 10.789 & 10.820 & 3.345 & 15.280 & High wall \\
\hline
\end{tabular}

- Pengambilan data foto udara menggunakan titik-titik GCP dan base GPS dengan metode real time kinematic $(R T K)$ menghasilkan data kontur/DEM/DTM yang lebih akurat dan presisi dibandingkan dengan pengambilan data foto udara yang tidak menggunakan $G C P$ dan base GPS, sehingga drone tidak terintegrasi dengan titik-titik ikat/kontrol/GCP, base GPS dan tidak dapat dilakukan pengambilan data foto udara secara real time kinematic $(R T K)$.

- Untuk memperoleh data yang lebih presisi dan akurat, titik-titik $G C P$ sebaiknya dipasang di setiap sudut dan titik pusat area objek.

- Overlap pengambilan data antar setiap foto udara harus $60 \%$. Jadi setiap foto harus saling overlap $60 \%$, agar setiap surface/objek dapat terambil dengan detil, sehingga tidak data yang kosong atau tidak terambil. 
- Pada saat pengolahan data hati-hati dalam menginput titik-titik GCP. Jika kurang teliti saat marking titik-titik $G C P$, kontur yang dihasilkan akan kurang teliti dan presisi.

- Pada saat pengolahan data harus memilih zona area yang tepat, agar kontur yang dihasilkan presisi berada di area objek yang di kaji.

- Dari tabel hasil pengolahan data terdapat variance posisi horizontal yang sangat besar pada area high wall, dikarenakan surface high wall yang tidak relatif data atau ada beberapa bench yang mengakibatkan pengambilan data foto udara tidak menggunakan titik-titik $G C P$ dan base GPS tidak presisi dan akurat.

- Pada area kontur yang jauh dari titik-titik GCP juga memperoleh variance posisi horizontal dan vertikal yang cukup besar pada section E-E' dan F-F'.

- Pada area kontur toe dan crest juga memperoleh variance posisi horizontal sedikit besar dikarenakan pembentukan kontur yang tidak presisi dan tidak akurat jika tidak menggunakan titik-titik GCP dan base GPS.

\section{E.2. Saran}

- Titik-titik $G C P$ dipasang dan disebar merata di area proyek dengan minimal di setiap sudut dan center area objek. Titik-titik GCP dan base GPS dipasang di area yang bebas obstacles dan base GPS dipsang pada area yang paling tinggi. Agar menghindari connection lost antara base GPS dengan GPS drone.

- Penelitian ini juga sebaiknya melibatkan alat-alat terestris seperti ETS (Electronic Total Station), TLS (Total Laser Scanner) maupun LIDAR (Light Detection and Ranging), agar komparasi yang dilakukan akan menghasilkan kesimpulan keakuratan dan presisi data dengan tingkat/selang kepercayaan data yang sangat tinggi.

- Pada saat pengolahan data menggunakan software agisoft/pix4D mapper/drone deploy/ APS menci/mission planner dan minscapelglobal mapper dilakukan dengan sangat hatihati, agar mengurangi dan menghindari human error.

- Peneltian ini sebaiknya dikembangkan dengan lebih detil lagi dengan menambahkan beberapa model titik-titik $G C P$ yang dipasang maupun menggunakan software yang lain (selain agisoft dan minescape), diharapkan memperoleh hasil kesimpulan yang lebih baik, presisi, dan akurat.

- Penelitian ini jauh dari hasil yang sempurna dan harapan penulis agar penelitian ini dapat dikembangkan menjadi yang lebih baik lagi.

\section{UCAPAN TERIMA KASIH}

- Alhamdulillah dipanjatkan puji dan syukur kepada Allah SWT. atas selesainya penelitian ini dengan lancar.

- Terima kasih kepada kedua orangtua Penulis atas doa dan dukungan selama Penulis mengerjakan dan menyelesikan penelitian ini.

- Terima kasih kepada PT Arutmin Indonesia, terutama kepada Pak Novriyadi (KTT Tambang Satui), Pak Agung Kurniawan (Superintendent Enginnering Satui), Pak Aris Kusnandar (Geodetic Supervisor Satui), Pak Iyus (Geologist Superintendent BPN), Mas Sigit (Geologist Supervisor BPN), teman-teman, dan rekan-rekan penulis di tambang Satui atas bimbingan dan semangat yang diberikan kepada Penulis untuk menyelesaikan penelitian ini.

\section{DAFTAR PUSTAKA}

Lilesand, dkk. 2004. Remote Sensing and Image Interpretation. Wisconsin: Willey. Purwadhi, F. S. 2001. Interpretasi Citra Digital. Jakarta: Grasindo.

Hasyim, A. W. 2009. Menetukan Titik Kontrol Tanah (GCP) dengan Menggunakan Teknik GPS dan Citra Satelit untuk Perencanaan Perkotaan. 
Rudianto, Bambang. 2011. Analisis Pengaruh Sebaran Ground Control Point Terhadap Ketelitian Objek pada Peta Citra Hasil Ortorektifikasi.

Kurniawan, Akbar, dkk. Pengaruh Jumlah dan Sebaran GCP pada Proses Rektifikasi Citra Worldwideview II.. Surabaya: ITS. 